\title{
Online Products Advertisement
}

\author{
M A Sugema ${ }^{1}$, N V Ramdhiani ${ }^{2}$ \\ \{muhamadadha@mahasiswa.unikom.ac.id ${ }^{1}$, vani@unikom.ac.id ${ }^{2}$ \} \\ Departemen Akuntansi, Universitas Komputer Indonesia, Indonesia ${ }^{1}$ \\ Departemen Manajemen, Universitas Komputer Indonesia, Indonesia ${ }^{2}$
}

\begin{abstract}
The purpose of this study is to explain whether installing products online can increase their product sales or not. This research method used by interviewing entrepreneurs; in this way, we can find out the results obtained by entrepreneurs. The result of this study shows that businessman advertises their products online in marketing their products. Entrepreneurs use the facility for advertising online because several websites provide advertisements for free and their products can be seen by people from various regions to get high sales opportunities. So, if sellers can advertise their products online, it can be seen by many people and has a high chance of increasing their sales figures.
\end{abstract}

Keywords: Products, Company, Transaction, Internet, Buyer

\section{Introduction}

We can find an advertisement every day when we use the internet. In an era of all-round online, we can make sales and purchases products whenever and wherever. It is easy and efficient, which makes it easier to shop customer's needs anywhere. The growing popularity of online product development invites a variety of information that can be utilized for resource in companies while making a decision [1]. Among all of the advantages which may be offered by electronic traders to retailers, the ability to offer consumers flexible and personal relationships is probably the most important [2].

Online means the State when a device such as a computer or mobile phone connected to the internet network. An online business can be done for free in public for free internet access with a laptop or mobile phone. The opposite of online business is an offline business such as a motorcycle repair shop, salons, restaurants, and more. Resources for doing online business is relatively small, or perhaps only need to spend internet access. Although only with free internet resources but the benefit can be very profitable. On the internet, there is a wide variety of online businesses [3]. The availability of product information about the production and price is accessible for buyers, sellers, manufacturers, and distributors. The manufacturer can choose where to produce and serve consumers; does not depend on where the consumer is located. A company can access the information and making business contacts without having to spend a high cost. Reduce transaction costs by having the system order, payment, logistics online, and automated [4]. An entrepreneur is a person who is creative, innovative, independent, in running his business, can manage and grow the business into a flourishing and excelled in a range of fields. The entrepreneur teaches how businesses can run independently [5]. E-Commerce as a transaction over the internet involves the transfer of goods, services, or information, which helps in the case of transactions that benefit the company. [6]. E-commerce is the technology in terms of the knowledge economy. Developing e-commerce is a choice for the economy to participate in the local market and eventually penetrate the global market, and bring significant 
results for the nation [7]. E-commerce can be used for a variety of markets and done through electronic networks, in the past, usually done through network ownership applications over a personal network [8].

This study aims to find out if we use the internet to advertise our products, whether it can increase the demand for goods and increase the sales of the products we sell. The method used by interviewing entrepreneurs, in this way we can find out the results obtained by entrepreneurs.

\section{Method}

This research method used interviews with 10 Respondents to obtain data to get information on whether traders using internet-based applications to sell products that are not selling or traders, as well as to find out if using online application whether or not the trader's income increases. Among the ten respondents, seven says sales of the product increased when sold online; three respondents said sales of its products remain the same due to lack of understanding describing the product.

\section{Results and Discussion}

To get the maximum results at the time of publishing the product to be sold, include a clear picture, there are details/product specifications, and categorize each product such as fashion, food, mobile, laptop, notebook, and other to improve customer's attraction towards products that are for sale. The buyer can do with the method of payment transfer to the bank account provided. Bookings can be done by computer or mobile devices connected to the internet.

For example, steps that must be done before the inventor can sell products. At the homepage, there are submenu, search field, and superior product, if you do not have an account, then it is necessary to create a new account to fill out data along with account number (Fig. 1).

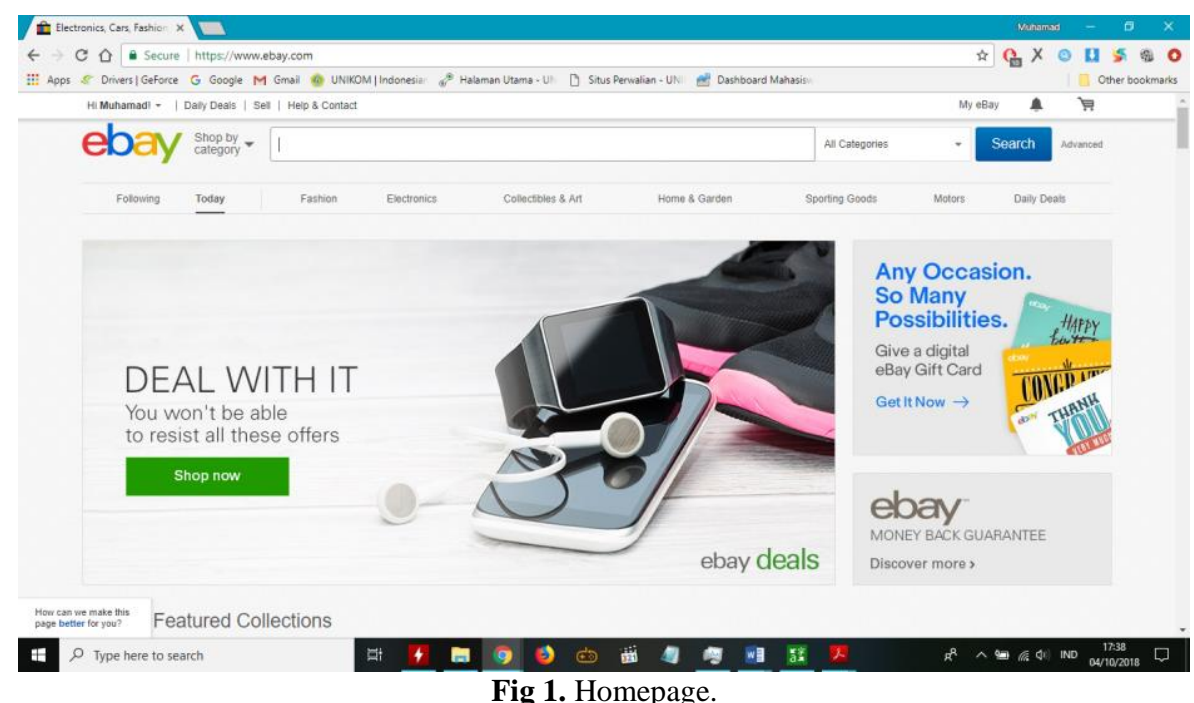

Fig 1. Homepage. 
If you want to sell, then you are required to select on the sell button. If we already have an account, then we are obliged to choose the product category that we want to sell (Fig. 2).

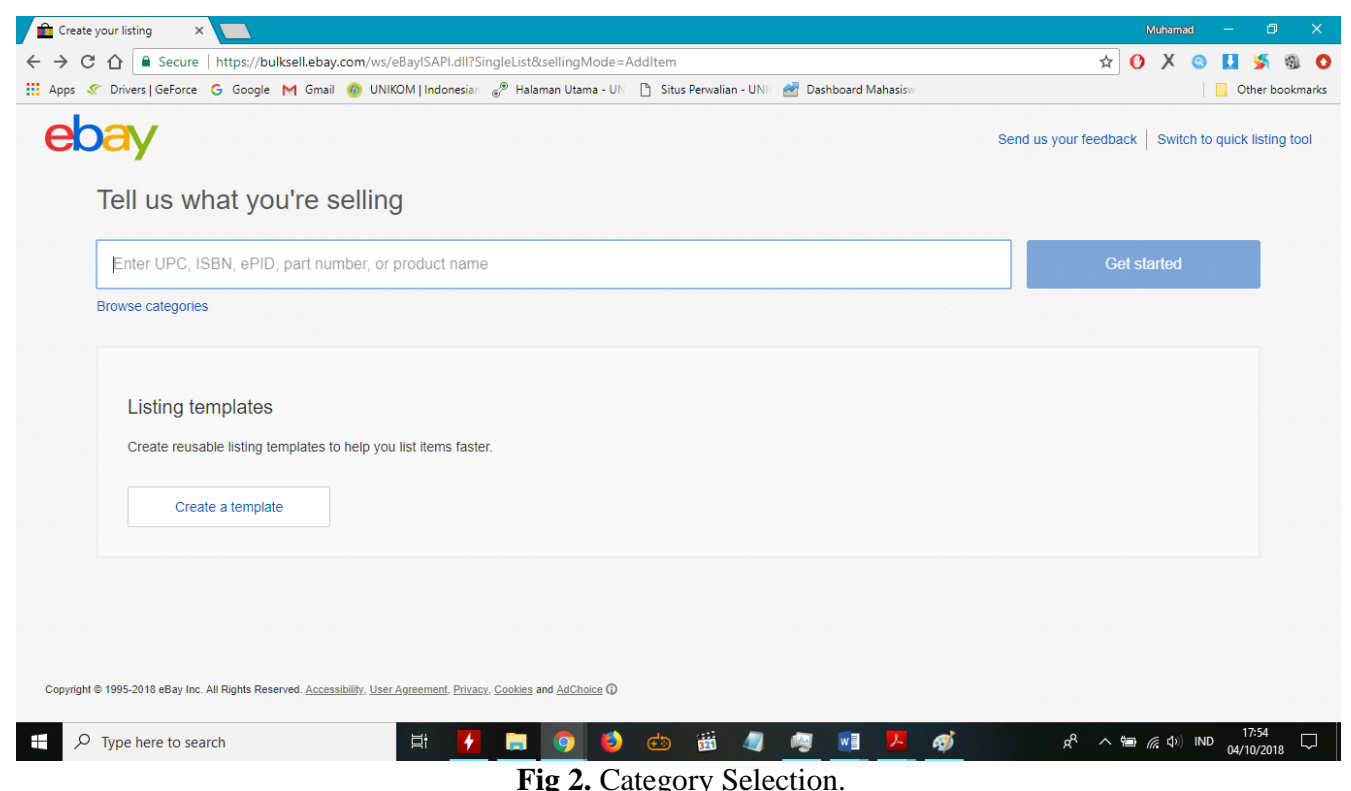

Fig 2. Category Selection.

For example, if we choose the category of phone sales, we are required to fill out a form, adding images, product prices, and describes the products that we sell (Fig. 3 and 4).

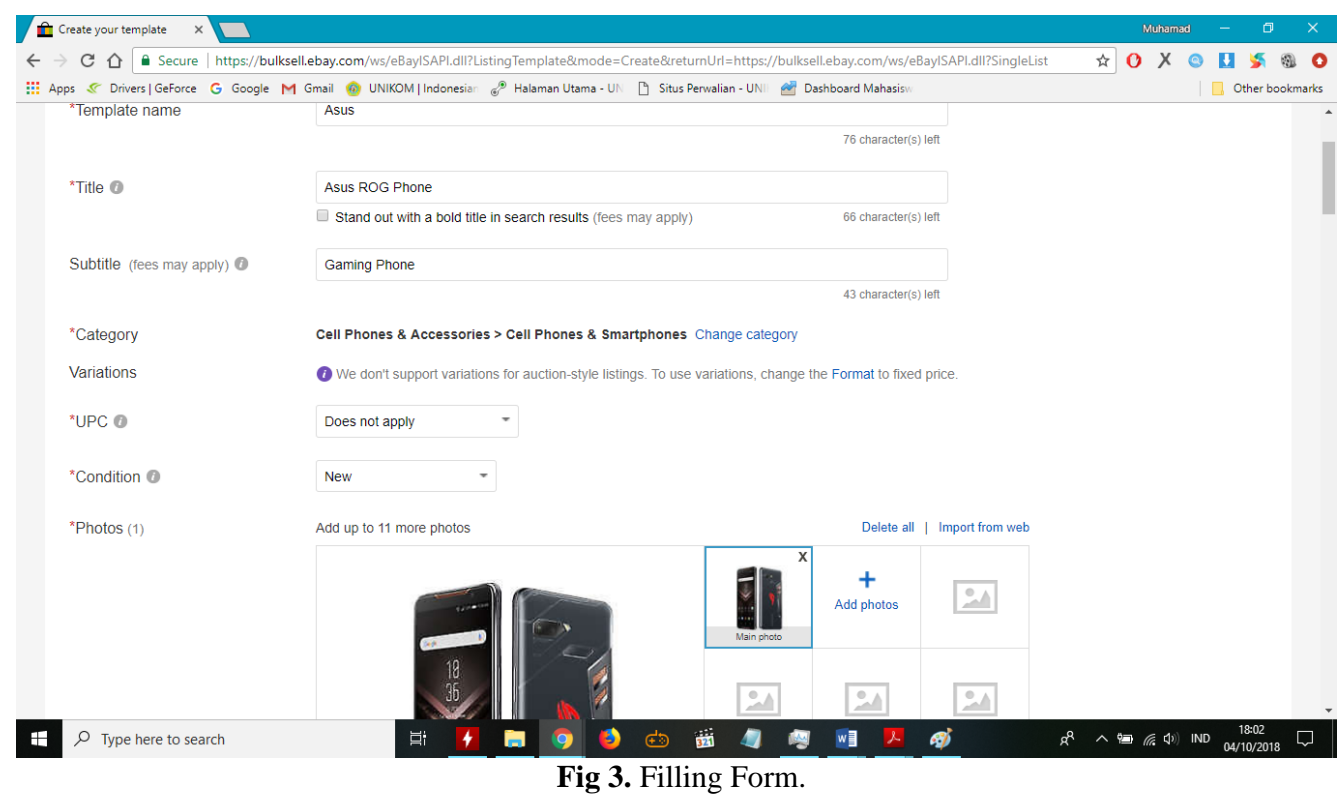




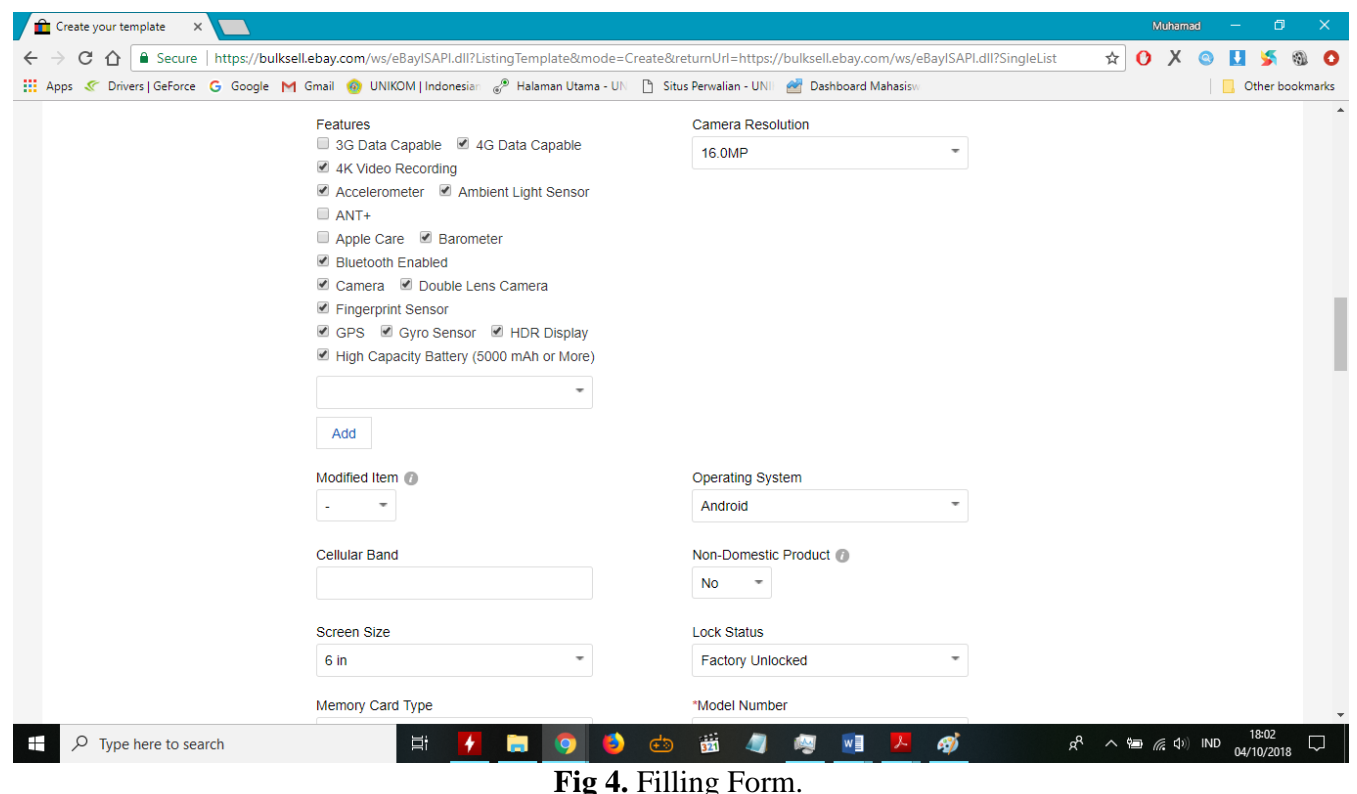

If you already filling the form, the next step saves the form by clicking Save template. (Fig. 5).

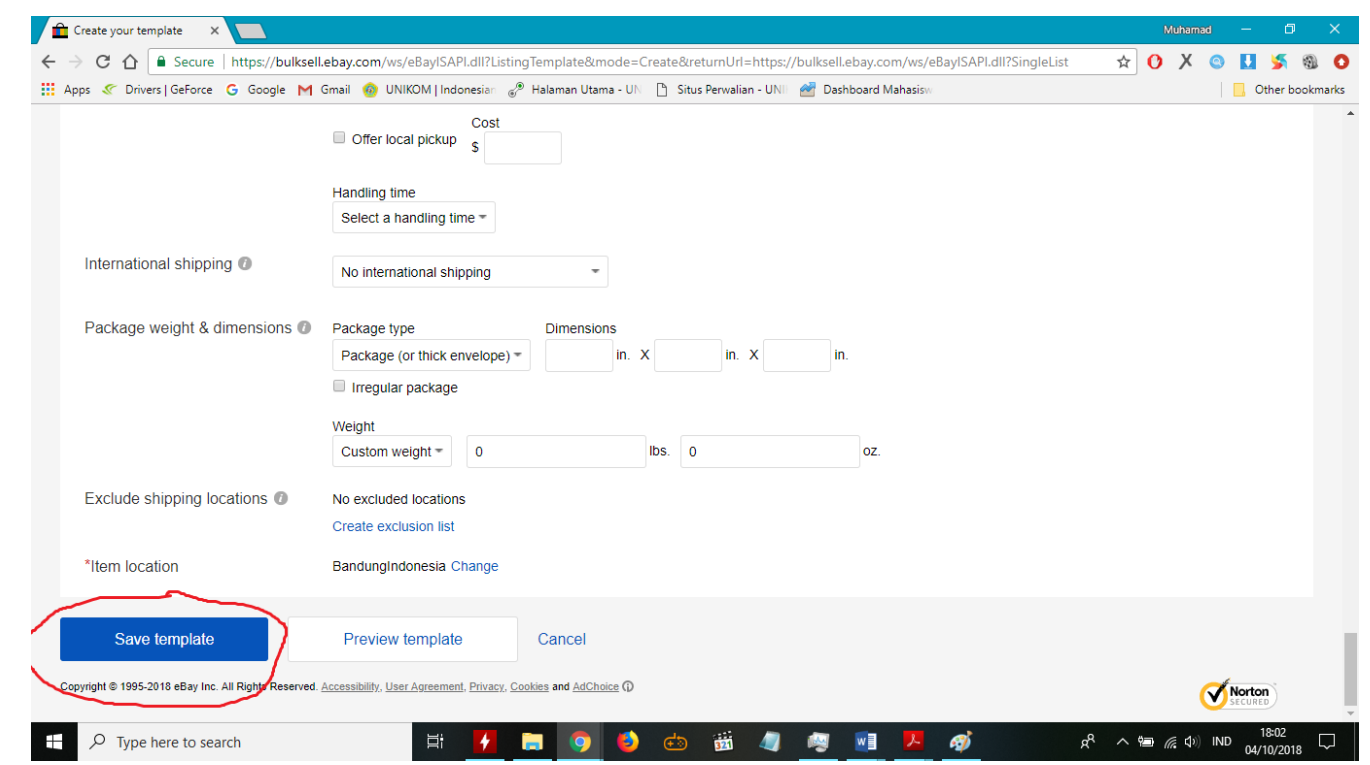

Fig 5. Save Template.

After clicking Save template then you have to wait for the process of product advertising that will be installed by the website. 
From the results of interviewing 10 respondents, the average respondent attempted to sell coffee products online and compare his earnings at the time of these products sold offline. (Fig. $6)$.

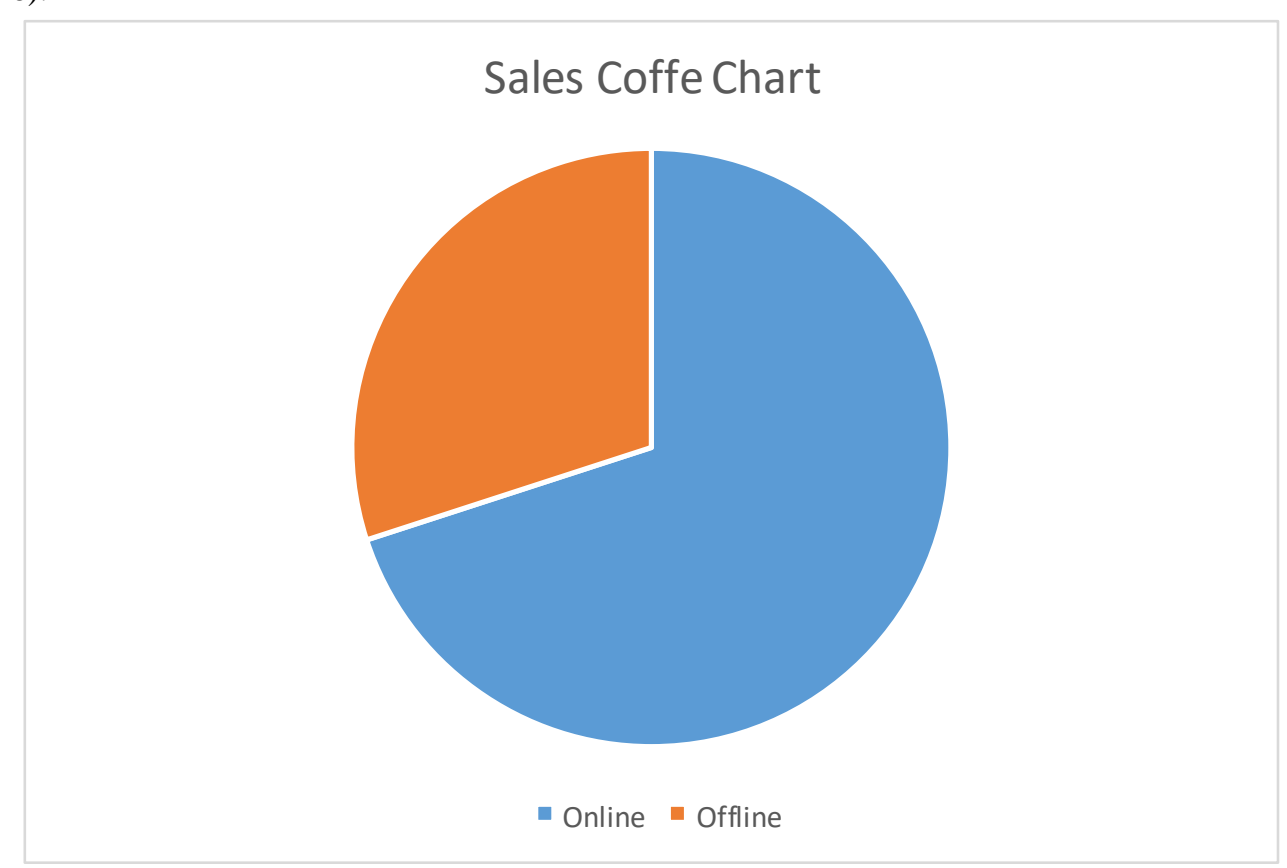

Fig 6. Sales Coffe Chart

From 10 copies sold, 7 of them were purchased online and 3 products purchased offline come to the store.

In selling the product, there is a comment field that usually there is a customer who reviews products or sellers. Consumers usually read the comments other people when deciding to buy, such as the recommendations system to trust the product to be purchased. In selling products online, consumers can ask other consumers for trusted vendors for their opinion about the product [9] Vending product evaluation depends on the opinions expressed by others. However, sometimes it can be a detriment to the product or brand that is sold. In some cases providing the there is a favorable evaluation product or brand. However, can also reflect the influence of other people's comments against products sold [10].

\section{Conclusion}

The development of technology can be beneficial for entrepreneurs to introduce products that are sold and can sell it anywhere, with any computer or mobile phone, entrepreneurs can introduce their products. Based on the results of the research, product sales online are pretty efficient in terms of time or cost. Although it quite efficient for sellers of products sometimes customers buying the product with online shop because there has not been a guarantee if the product is bought to the destination, because of the case of the crime of online transactions. 


\section{Acknowledgments}

The authors are grateful to the mentor who has been guiding in the writing of scientific works and providing the opportunity to write scientific papers, and to respondents who are willing to do the interview and take the time.

\section{References}

[1] Dellarocas, Chrysanthos, Xiaoquan Zhang, and Neveen F. Awad.: Exploring the value of online product reviews in forecasting sales: The case of motion pictures. Journal of Interactive marketing 21.4. 23-45. (2007)

[2] Senecal, S., \& Nantel, J.: The influence of online product recommendations on consumers' online choices. Journal of retailing, 80(2), 159-169. (2004)

[3] Daniel, E. M., Domenico, M. D., \& Sharma, S.: Effectuation and home-based online business entrepreneurs. International Small Business Journal, 33(8), 799-823. (2015)

[4] Clark, R.: World-system mobility and economic growth, 1980-2000. Social Forces, 88(3), 11231151. (2010)

[5] Oosterbeek, H., Van Praag, M., \& Ijsselstein, A.: The impact of entrepreneurship education on entrepreneurship skills and motivation. European economic review, 54(3), 442-454. (2010)

[6] Brian C. Satterlee, E-Commerce a Knowledge Base.: Defining E-Commerce, pp.1. United States of America. (2001)

[7] Zhen Qin, Introduction to E-Commerce.: Fundamentals of E-Commerce, pp.1. Thisngsua, Beijing. (2009)

[8] Bharat Bhasker, to advertise Commerce Framework Technologies and Applications.: Introduction to Electronic Commerce, pp.1. New Delhi, India. (2009)

[9] Huang, J. H., \& Chen, Y. F.: Herding in online product choice. Psychology \& Marketing, 23(5), 413-428. (2006)

[10] Moe, W. W., \& Schweidel, D. A.: Online product opinions: Incidence, evaluation, and evolution. Marketing Science, 31(3), 372-386. (2012) 